\title{
A study of Pescar's univalence criteria for space of analytic functions
}

\author{
Imran Faisal and Maslina Darus ${ }^{*}$
}

* Correspondence: maslina@ukm. my

School of Mathematical Sciences, Faculty of Science and Technology, Universiti Kebangsaan Malaysia, Bangi 43600 Selangor D. Ehsan, Malaysia

\section{Abstract}

An attempt has been made to give a criteria to a family of functions defined in the space of analytic functions to be univalent. Such criteria extended earlier univalence criteria of Pescar's-type of analytic functions.

2000 MSC: $30 C 45$.

Keywords: analytic functions, univalent functions, integral operator

\section{Introduction and preliminaries}

Let $A$ denote the class of analytic functions of the form $f(z)=z+\sum_{k=2}^{\infty} a_{k} z^{k}$ in the open unit disk $\mathbb{U}=\{z:|z|<1\}$ normalized by $f(0)=f^{\prime}(0)-1=0$.

We denote by $S$ the subclass of $A$ consisting of functions which are univalent in $\mathbb{U}$.

The results in this communication are motivated by Pescar [1]. In [1], a new criteria for an analytic function to be univalent is introduced which is true only for two fixed natural numbers. Then, Breaz and Breaz [2] introduced a new integral operator using product $n$-multiply analytic functions and gave another univalence criteria for such analytic integral operators. Using such integral operator, we extend the criteria given by Pescar in 2005 and prove that it is true for any two consecutive natural numbers.

First, we recall the main results of Pescar introduced in 1996 and later 2005 as follow:

Lemma 1.1. [1,3] Let $\alpha$ be a complex number with $\operatorname{Re} \alpha>0$ such that $c \in \mathbb{C}$, $|c| \leq 1, c \neq-1$. If $f \in A$ satisfies the condition

$$
\left.|c| z\right|^{2 \alpha}+\left(1-|z|^{2 \alpha}\right) \frac{z f^{\prime \prime}(z)}{\alpha f^{\prime}(z)} \mid \leq 1, \quad \forall_{z} \in \mathbb{U},
$$

then the function $\left(F_{\alpha}(z)\right)^{\alpha}=\alpha \int_{0}^{z} t^{\alpha-1} f^{\prime}(t) d t$ is analytic and univalent in $\mathbb{U}$.

Lemma 1.2. [1] Let the function $f \in A$ satisfies $\left|\frac{z^{2} f^{\prime}(z)}{f^{2}(z)}-1\right| \leq 1, \quad \forall z \in \mathbb{U}$. Also, let $\alpha \in \mathbb{R}\left(\alpha \in\left[1, \frac{3}{2}\right]\right)$ and $c \in \mathbb{C}$. If $|c| \leq \frac{3-2 \alpha}{\alpha}(c \neq-1)$ and $|g(z)| \leq 1$, then the function $G_{a}(z)$ defined by $\left(G_{\alpha}(z)\right)^{\alpha}=\alpha \int_{0}^{z}[f(t)]^{\alpha-1}$ is in the univalent function class $S$.

Lemma 1.3. [4] If $f \in A$ satisfies the condition $\left|\frac{z^{2} f^{\prime}(z)}{f^{2}(z)}-1\right| \leq 1, \quad \forall z \in \mathbb{U}$, then the function $f$ is univalent in $\mathbb{U}$.

(c) 2011 Faisal and Darus; licensee Springer. This is an Open Access article distributed under the terms of the Creative Commons Attribution License (http://creativecommons.org/licenses/by/2.0), which permits unrestricted use, distribution, and reproduction in any medium, provided the original work is properly cited. 
Lemma 1.4. (Schwarz Lemma) Let the analytic function $f$ be regular in the open unit disk $\mathbb{U}$ and let $f(0)=0$. If $|f(z)| \leq 1,(z \in \mathbb{U})$ then $|f(z)| \leq|z|$ where the equality holds true only if $f(z)=k z$ and $|k|=1$.

Breaz (cf., [2,5]) introduced a family of integral operators for $f_{i} \in A$ univalent in $\mathbb{U}$ denoted by $G_{n, \alpha}$ such that

$$
G_{n, \alpha}(z)=\left[(n(\alpha-1)+1) \int_{0}^{z}\left[f_{1}(t)\right]^{\alpha-1} \cdots\left[f_{n}(t)\right]^{\alpha-1} d t\right]^{\frac{1}{n(\alpha-1)+1}}, \quad f_{i} \in A .
$$

In the case of $n=1$, the operator $G_{n, \alpha}$ becomes identical to the operator $G_{\alpha}$ given in Lemma 1.2 which was introduced by Pescar in 1996.

\section{Main univalence criteria for analytic function}

In this section, we make a criteria for space of analytic functions to be univalent. We give proof and applications only for the first theorem and for the remaining theorems we use the same techniques.

Theorem 2.1. Let $f_{i} \in A,\left|\frac{z^{2} f^{\prime}(z)}{\left(f_{i}(z)\right)^{2}}-1\right| \leq 1, \quad z \in \mathbb{U}$ for all $i=\{1,2, \ldots, n\}$.

If

$$
|c| \leq 1+\left(\frac{\alpha-1}{\alpha}\right)\left(\frac{4 M\left(3^{n}-2^{n}\right)}{2^{n}}\right) n, \quad \alpha \in \mathbb{R}, c \in \mathbb{C}
$$

and

$$
\left|f_{i}(z)\right| \leq M, \quad \forall i \text { and } M \geq 1 .
$$

Then, the family of functions $f$ denoted by $G_{n, \alpha}$ belong to the class $S$.

Theorem 2.2. Let $f_{i} \in A,\left|\frac{z^{2} f_{i}^{\prime}(z)}{\left(f_{i}(z)\right)^{2}}-1\right| \leq 1, \quad z \in \mathbb{U}$ for all $i=\{1,2, \ldots, n\}$.

If

$$
|c| \leq 1+\left(\frac{\alpha-1}{\alpha}\right)\left(\frac{6 M\left(4^{n}-3^{n}\right)}{3^{n}}\right) n, \quad \alpha \in \mathbb{R}, c \in \mathbb{C}
$$

and

$$
\left|f_{i}(z)\right| \leq M, \quad \forall i \text { and } M \geq 1 .
$$

Then, the family of functions $f$ denoted by $G_{\mathrm{n}, \alpha}$ belong to the class $S$.

Theorem 2.3. Let $f_{i} \in A,\left|\frac{z^{2} f_{i}^{\prime}(z)}{\left(f_{i}(z)\right)^{2}}-1\right| \leq 1, \quad z \in \mathbb{U}$ for all $i=\{1,2, \ldots, n\}$.

If

$$
|c| \leq 1+\left(\frac{\alpha-1}{\alpha}\right)\left(\frac{8 M\left(5^{n}-4^{n}\right)}{4^{n}}\right) n, \quad \alpha \in \mathbb{R}, c \in \mathbb{C}
$$

and

$$
\left|f_{i}(z)\right| \leq M, \quad \forall i \text { and } M \geq 1 .
$$

Then, the family of functions $f$ denoted by $G_{n, \alpha}$ belong to the class $S$. 
Proof of Theorem 2.1. Since for each $f_{i} \in A$ implies

$$
\frac{f_{i}(z)}{z}=1+\sum_{2}^{\infty} a_{n} z^{n-1}, \quad \forall i
$$

and

$$
\frac{f_{i}(z)}{z}=1 \quad \text { at } z=0, \forall i
$$

We can write

$$
\prod_{i=1}^{n} \frac{f_{i}(z)}{z}=1 \quad \text { at } z=0 .
$$

Now suppose that

$$
F(z)=\int_{0}^{z}\left[\frac{f_{1}(t)}{t}\right]^{\alpha-1} \cdots\left[\frac{f_{n}(t)}{t}\right]^{\alpha-1} d t
$$

and taking logarithmic derivative and doing some mathematics we get

$$
\begin{aligned}
F^{\prime \prime}(z) & =(\alpha-1) \sum_{i=2}^{\infty}\left(\frac{f_{i}(z)}{z}\right)^{\alpha-2}\left(\frac{z f^{\prime}{ }_{i}(z)-f_{i}(z)}{z^{2}} \prod_{j=1}^{n}\left(\frac{f_{j}(z)}{(z)}\right)^{\alpha-1}\right), \\
\Rightarrow & \frac{z F^{\prime \prime}(z)}{F^{\prime}(z)}=(\alpha-1) \sum_{i=2}^{\infty}\left(\frac{z f_{i}^{\prime}(z)}{f_{i}(z)}-1\right), \\
\Rightarrow & \left|\frac{z F^{\prime \prime}(z)}{F(z)}\right| \leq(\alpha-1) \sum_{i=2}^{\infty}\left(\left|\frac{z^{2} f_{i}^{\prime}(z)}{\left.f_{i}(z)\right)^{2}}\right|\left|\frac{f_{i}(z)}{z}\right|+1\right) .
\end{aligned}
$$

Using hypothesis of Theorem 2.1 such as $\left|\frac{z^{2} f_{i}^{\prime}(z)}{\left(f_{i}(z)\right)^{2}}\right| \leq 2,\left|f_{i}(z)\right| \leq M, \forall i$ for $M \geq 1$ and after doing calculation we get

$$
\begin{aligned}
& \left|\frac{z F^{\prime \prime}(z)}{F^{\prime}(z)}\right| \leq(\alpha-1) \sum_{i=1}^{m}(2 M+(2 M+1)), \quad \because 2 M \geq 1, \\
\Rightarrow & \left|\frac{z F^{\prime \prime}(z)}{F^{\prime}(z)}\right| \leq(\alpha-1) \sum_{i=1}^{m}\left(2 M+\left(2 M+\frac{2 M}{2}\right)+\left(3 M+\frac{3 M}{2}\right)\right), \quad \because 3 M / 2 \geq 1 \\
\Rightarrow & \left|\frac{z F^{\prime \prime}(z)}{F^{\prime}(z)}\right| \leq(\alpha-1) \sum_{i=1}^{m}\left(2 M+3 M+\frac{9 M}{2} M+\cdots+n \text {th term }\right) .
\end{aligned}
$$

Therefore, by Lemma 1.1, we get

$$
\begin{aligned}
\left.|c| z\right|^{2 \alpha}+\left(1-|z|^{2 \alpha}\right) \frac{z F^{\prime \prime}(z)}{\alpha F^{\prime}(z)} \mid & \leq|c|+\frac{1}{\alpha}\left|\frac{z F^{\prime \prime}(z)}{F^{\prime}(z)}\right| \leq|c|+\frac{1}{\alpha}\left|\frac{z F^{\prime \prime}(z)}{F^{\prime}(z)}\right|, \\
\left.\Rightarrow|c| z\right|^{2 \alpha}+\left(1-|z|^{2 \alpha}\right) \frac{z F^{\prime \prime}(z)}{\alpha F^{\prime}(z)} \mid & \leq|c|+\frac{1}{\alpha}\left|\frac{z F^{\prime \prime}(z)}{F^{\prime}(z)}\right|
\end{aligned}
$$


and

$$
\left.|c| z\right|^{2 \alpha}+\left(1-|z|^{2 \alpha}\right) \frac{z F^{\prime \prime}(z)}{\alpha F^{\prime}(z)}|\leq| c \mid+\left(\frac{\alpha-1}{\alpha}\right) \sum_{i=1}^{n}\left(2 M+3 M+\frac{9}{2} M+\cdots+n \text {th term }\right) .
$$

Hence, after calculation, we have

$$
\begin{aligned}
&\left.|c| z\right|^{2 \alpha}+\left(1-|z|^{2 \alpha}\right) \frac{z F^{\prime \prime}(z)}{\alpha F^{\prime}(z)} \mid \leq|c|+\left(\frac{\alpha-1}{\alpha}\right) \sum_{i=1}^{n}\left(\frac{4 M\left(3^{n}-2^{n}\right)}{2^{n}}\right) \\
& \text { or }\left.|c| z\right|^{2 \alpha}+\left(1-|z|^{2 \alpha}\right) \frac{z F^{\prime \prime}(z)}{\alpha F^{\prime}(z)}|\leq| c \mid+\left(\frac{\alpha-1}{\alpha}\right) n\left(\frac{4 M\left(3^{n}-2^{n}\right)}{2^{n}}\right),
\end{aligned}
$$

and again using the hypothesis of Theorem 2.1 we get

$$
\left.|c| z\right|^{2 \alpha}+\left(1-|z|^{2 \alpha}\right) \frac{z F^{\prime \prime}(z)}{\alpha F^{\prime}(z)} \mid \leq 1,
$$

and hence proved.

Theorem 2.4. Let $f_{i} \in A,\left|\frac{z^{2} f_{i}^{\prime}(z)}{\left(f_{i}(z)\right)^{2}}-1\right| \leq 1, \quad z \in \mathbb{U}$ for all $i=\{1,2, \ldots, n\}$.

If

$$
|c| \leq 1+\left(\frac{\alpha-1}{\alpha}\right)\left(\frac{6 M\left(3^{n}-2^{n}\right)}{3^{n}}\right) n, \quad \alpha \in \mathbb{R}, c \in \mathbb{C}
$$

and

$$
\left|f_{i}(z)\right| \leq M, \quad \forall i \text { and } M \geq 1
$$

Then, the family of functions $f$ denoted by $G_{n, \alpha}$ belong to the class $S$.

Proof. Using the proof of Theorem 2.1, we have

$$
\left|\frac{z F^{\prime \prime}(z)}{F(z)}\right| \leq(\alpha-1) \sum_{i-2}^{\infty}\left(\left|\frac{z^{2} f_{i}^{\prime}(z)}{\left(f_{i}(z)\right)^{2}}\right|\left|\frac{f_{i}(z)}{z}\right|+1\right) .
$$

Again, using the hypothesis, we get

$$
\begin{aligned}
& \left|\frac{z F^{\prime \prime}(z)}{F^{\prime}(z)}\right| \leq(\alpha-1) \sum_{i=1}^{m}(2 M+(2 M+1)), \quad \because 2 M \geq 1, \\
\Rightarrow & \left|\frac{z F^{\prime \prime}(z)}{F^{\prime}(z)}\right| \leq(\alpha-1) \sum_{i-1}^{m}\left(2 M+\left(M+\frac{M}{2}\right)+\left(M+\frac{2 M}{9}\right)\right), \\
\Rightarrow & \left|\frac{z F^{\prime \prime}(z)}{F^{\prime}(z)}\right| \leq(\alpha-1) \sum_{i=1}^{m}\left(2 M+\frac{4}{3} M+\frac{8}{9} M+\cdots+n \text {th term }\right) .
\end{aligned}
$$

Thus, we have

$$
\begin{aligned}
\left.|c| z\right|^{2 \alpha}+\left(1-|z|^{2 \alpha}\right) \frac{z F^{\prime \prime}(z)}{\alpha F^{\prime}(z)}|\leq| c\left|+\frac{1}{\alpha}\right| \frac{z F^{\prime \prime}(z)}{F^{\prime}(z)}|\leq| c\left|+\frac{1}{\alpha}\right| \frac{z F^{\prime \prime}(z)}{F^{\prime}(z)} \mid, \\
\left.\Rightarrow|c| z\right|^{2 \alpha}+\left(1-|z|^{2 \alpha}\right) \frac{z F^{\prime \prime}(z)}{\alpha F^{\prime}(z)}|\leq| c\left|+\frac{1}{\alpha}\right| \frac{z F^{\prime \prime}(z)}{F^{\prime}(z)} \mid
\end{aligned}
$$


and

$$
\left.|c| z\right|^{2 \alpha}+\left(1-|z|^{2 \alpha} \frac{z F^{\prime \prime}(z)}{\alpha F^{\prime}(z)}|\leq| c \mid+\left(\frac{\alpha-1}{\alpha}\right) \sum_{i=1}^{n}\left(2 M+\frac{4}{3} M+\frac{8}{9} M+\cdots+n \text {th term }\right),\right.
$$

which implies that

$$
\begin{aligned}
\left.|c| z\right|^{2 \alpha}+\left(1-|z|^{2 \alpha}\right) \frac{z F^{\prime \prime}(z)}{\alpha F^{\prime}(z)}|\leq| c \mid+\left(\frac{\alpha-1}{\alpha}\right) \sum_{i=1}^{n}\left(\frac{6 M\left(3^{n}-2^{n}\right)}{3^{n}}\right) & \leq|c|+\left(\frac{\alpha-1}{\alpha}\right) n\left(\frac{6 M\left(3^{n}-2^{n}\right)}{3^{n}}\right) .
\end{aligned}
$$

Again, using the hypothesis of Theorem 2.1, we get

$$
\left.|c| z\right|^{2 \alpha}+\left(1-|z|^{2 \alpha}\right) \frac{z F^{\prime \prime}(z)}{\alpha F^{\prime}(z)} \mid \leq 1,
$$

and hence proved.

Similarly, we proved the following theorems:

Theorem 2.5. Let $f_{i} \in A,\left|\frac{z^{2} f^{\prime}(z)}{\left(f_{i}(z)\right)^{2}}-1\right| \leq 1, \quad z \in \mathbb{U}$ for all $i=\{1,2, \ldots, n\}$.

If

$$
|c| \leq 1+\left(\frac{\alpha-1}{\alpha}\right)\left(\frac{8 M\left(4^{n}-3^{n}\right)}{4^{n}}\right) n, \quad \alpha \in \mathbb{R}, c \in \mathbb{C}
$$

and

$$
\left|f_{i}(z)\right| \leq M, \quad \forall i \text { and } M \geq 1
$$

Then, the family of functions $f$ denoted by $G_{n, \alpha}$ belong to the class $S$.

Theorem 2.5. Let $f_{i} \in A,\left|\frac{z^{2} f_{i}^{\prime}(z)}{\left(f_{i}(z)\right)^{2}}-1\right| \leq 1, \quad z \in \mathbb{U}$ for all $i=\{1,2, \ldots, n\}$.

If

$$
|c| \leq 1+\left(\frac{\alpha-1}{\alpha}\right)\left(\frac{10 M\left(5^{n}-4^{n}\right)}{5^{n}}\right) n, \quad \alpha \in \mathbb{R}, c \in \mathbb{C}
$$

and

$$
\left|f_{i}(z)\right| \leq M, \quad \forall i \text { and } M \geq 1
$$

Then, the family of functions $f$ denoted by $G_{n, \alpha}$ belong to the class $S$.

\section{Applications of univalence criteria}

Considering $n=1$ in Theorem 2.1, we obtain the following application:

Corollary 3.1. Let $f_{i} \in A,\left|\frac{z^{2} f^{\prime}{ }_{i}(z)}{\left(f_{i}(z)\right)^{2}}-1\right| \leq 1, \quad z \in \mathbb{U}$ for all $i=\{1,2, \ldots, n\}$.

If

$$
|c| \leq 1+\left(\frac{\alpha-1}{\alpha}\right)(2 M), \quad \alpha \in \mathbb{R}, c \in \mathbb{C}
$$


and

$$
\left|f_{i}(z)\right| \leq 1, \quad \forall i .
$$

Then, the family of functions $f$ denoted by $G_{n, \alpha}$ belong to the class $S$.

Considering $M=n=11$ in Theorem 2.1, we obtain second application as follow:

Corollary 3.2. Let $f_{i} \in A,\left|\frac{z^{2} f_{i}^{\prime}(z)}{\left(f_{i}(z)\right)^{2}}-1\right| \leq 1, \quad z \in \mathbb{U}$ for all $i=\{1,2, \ldots, n\}$.

If

$$
|c| \leq\left(\frac{3 \alpha-2}{\alpha}\right), \quad \alpha \in \mathbb{R}, c \in \mathbb{C}
$$

and

$$
\left|f_{i}(z)\right| \leq 1, \quad \forall i .
$$

Then, the family of functions $f$ denoted by $G_{n, \alpha}$ belong to the class $S$.

Considering $M=1$ in Theorem 2.1, we obtain third application such as:

Corollary 3.3. Let $f_{i} \in A,\left|\frac{z^{2} f^{\prime}(z)}{\left(f_{i}(z)\right)^{2}}-1\right| \leq 1, \quad z \in \mathbb{U}$ for all $i=\{1,2, \ldots, n\}$.

If

$$
|c| \leq 1+\left(\frac{\alpha-1}{\alpha}\right)\left(\frac{\left(3^{n}-2^{n}\right)}{2^{n-2}}\right) n, \quad \alpha \in \mathbb{R}, c \in \mathbb{C}
$$

and

$$
\left|f_{i}(z)\right| \leq 1, \quad \forall i
$$

Then, the family of functions $f$ denoted by $G_{n, \alpha}$ belong to the class $S$.

If we substitute $n=1$ and $M=n=1$ in Theorem 2.4, we get the results of Corollaries 3.1 and 3.2, respectively.

Other work related to integral operators concerning on univalence criteria and properties can be found in [6,7].

\section{Acknowledgements}

The study presented here was fully supported by the UKM-ST-06-FRGS0244-2010.

\section{Authors' contributions}

The first author is currently a PhD student under supervision of the second author and jointly worked on the results. All authors read and approved the final manuscript.

\section{Competing interests}

The authors declare that they have no competing interests.

Received: 26 June 2011 Accepted: 10 November 2011 Published: 10 November 2011

\section{References}

1. Pescar, V: On the univalence of some integral operators. J Indian Acad Math. 27, 239-243 (2005)

2. Breaz, D, Breaz, N: Univalence of an integral operator. Mathematica (Cluj). 47(70), 35-38 (2005)

3. Pescar, $V:$ A new generalization of Ahlfors's and Becker's criterion of univalence. Bull Malaysian Math Soc. 19, 53-54 (1996)

4. Ozaki, S, Nunokawa, M: The Schwarzian derivative and univalent func-tions. Proc Am Math Soc. 33, 392-394 (1972). doi:10.1090/S0002-9939-1972-0299773-3

5. Breaz, D: Integral Operators on Spaces of Univalent Functions. Publishing House of the Romanian Academy of Sciences, Bucharest (in Romanian) (2004)

6. Darus, M, Faisal, I: A study on Becker's univalence criteria. Abstr Appl Anal 2011, 13 (2011). Article ID759175, 
7. Mohammed, A, Darus, M: Starlikeness properties for a new integral operator for meromorphic functions. J Appl Math 2011, 8 (2011). Article ID 804150,

doi:10.1186/1029-242X-2011-109

Cite this article as: Faisal and Darus: A study of Pescar's univalence criteria for space of analytic functions. Journal of Inequalities and Applications 2011 2011:109.

Submit your manuscript to a SpringerOpen ${ }^{\odot}$ journal and benefit from:

- Convenient online submission

- Rigorous peer review

- Immediate publication on acceptance

- Open access: articles freely available online

- High visibility within the field

- Retaining the copyright to your article

Submit your next manuscript at $\gg$ springeropen.com 